\title{
Analysis of Natural Convection in Porous Media for Thermal Storage Using Darcy- Brinkman-Forcheimer Formulation
}

\author{
Mohamed Belhadj*, Aissa Atia, Ahmed Benchatti \\ Laboratory of Mechanics, University Amar Telidji, Laghouat 03000, Algeria \\ Corresponding Author Email: m.belhadj@lagh-univ.dz
}

https://doi.org/10.18280/mmep.070109

Received: 18 May 2019

Accepted: 3 January 2020

\section{Keywords: \\ Darcy-Brinkman-Forcheimer, heat convection, porosity, porous media}

\begin{abstract}
This numerical study deals with heat convection in a porous media. The heat transfer is modeled using Darcy-Brinkman-Forcheimer formulation. A CFD code based on the finite volume method is used to solve the mathematical set of equations governing air flow and convective heat transfer in the porous media. The numerical predictions are validated by comparison with results available in the literature. Parameters governing heat transfer and fluid flow are investigated (Rayleigh number, Darcy number and porosity). Increasing Rayleigh and Darcy numbers resulted in enhancing the heat transfer rate but the convective heat transfer rate decreased with increasing porosity.
\end{abstract}

\section{INTRODUCTION}

Heat transfer by convection in porous media has attracted researchers for the last decades. It has various applications such as geothermal, crystal growth, oil industry, drying and building thermal applications. Nield and Bejan has reviewed a detailed literature related to convective heat transfer in porous media [1]. Numerical studies are focused then on a differentially heated porous cavity. Loganathan and Sivapoornapriya [2] studied heat transfer and fluid flow in porous medium. They considered an impulsively started vertical plate. Ma et al. [3] investigated a natural convection problem in a square cavity filled with porous media. They used the Lattice Boltzmann method to solve numerically the mathematical model. Horton and Rogers [4] and Lapwood [5] are the pioneers to investigate heat transfer in porous media. Revnic et al. [6] analyzed heat convection in infinite rectangular cavity of bi-dispersed porous medium (BDPM), they used a mathematical model proposed by Nield and Kuznetsov [7] and Rees et al. [8]. Rayleigh numbers investigated were less than $10^{3}$. This study showed that heat transfer is done mainly by conduction for lower Ra values. Both thermal conductivity and Darcy number have great influence on heat convection central cells. Bahloul [9] studied fluid flow in a vertical cavity with porous media. The vertical walls were differentially heated whereas the horizontal walls were kept adiabatic. Rayleigh number and the aspect ratio had significant effect on flow structure. Kalla et al. [10] investigated numerically heat convection in a very long horizontal porous layer. The porous layer walls were exposed to uniform heat flux. The model of Darcy was used. Finite difference was used to solve the numerical model. The effect of Rayleigh number on heat transfer in the porous layer was investigated. Nawaf et al. [11] conducted a numerical study on transient heat transfer in porous media. The model of Darcy was used with Boussinesq approximation of a standard fluid. The hot wall was exposed to fluctuated heat flux whereas the cold wall was kept at constant temperature. The other two walls were kept adiabatic. Streamlines, isothermals and Nusselt number were analyzed.

However, there are only few works that deal with the effect of porosity in porous media. Thus, the objective of this study is to investigate both heat transfer and fluid flow in a cavity filled with porous media using Darcy Brinkman-Forcheimer formulation.

\section{MATHEMATICAL MODEL}

The air flow is assumed to be two-dimensional in a cavity filled with porous media (Figure 1). Fluid properties are supposed to be constant. The fluid is considered to be incompressible and Newtonian. Boussinesq approximation is applied. Heat generation and radiation effects are neglected in the present study.

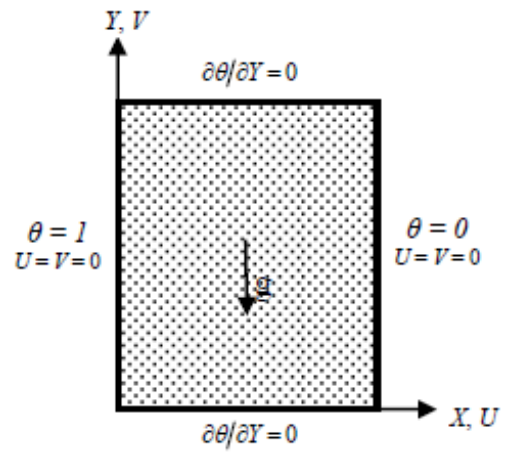

Figure 1. Schematic diagram of the cavity and boundary conditions

The mathematical model is composed of [12]:

Continuity equation

$$
\frac{\partial U}{\partial X}+\frac{\partial V}{\partial Y}=0
$$


$\mathrm{X}$ - Momentum equation

$$
\begin{aligned}
\frac{1}{\varepsilon^{2}} U \frac{\partial U}{\partial X}+\frac{1}{\varepsilon^{2}} V \frac{\partial U}{\partial Y}= & -\frac{\partial P}{\partial X}+\frac{\operatorname{Pr}}{\varepsilon}\left(\frac{\partial^{2} U}{\partial X^{2}}+\frac{\partial^{2} U}{\partial Y^{2}}\right) \\
& -\frac{\operatorname{Pr}}{D a} j U-\frac{1.75}{\sqrt{150}} \frac{\sqrt{U^{2}+V^{2}}}{\sqrt{D a}} \frac{U}{\varepsilon^{3 / 2}}
\end{aligned}
$$

Y- Momentum equation

$$
\begin{aligned}
\frac{1}{\varepsilon^{2}} U \frac{\partial V}{\partial X}+\frac{1}{\varepsilon^{2}} V \frac{\partial V}{\partial Y}= & -\frac{\partial P}{\partial Y}+\frac{\operatorname{Pr}}{\varepsilon}\left(\frac{\partial^{2} U}{\partial X^{2}}+\frac{\partial^{2} U}{\partial Y^{2}}\right) \\
& -\frac{\operatorname{Pr}}{D a} j V-\frac{1.75}{\sqrt{150}} \frac{\sqrt{U^{2}+V^{2}}}{\sqrt{D a}} \frac{V}{\varepsilon^{3 / 2}}+R a \operatorname{Pr} \theta
\end{aligned}
$$

Energy equation

$$
U \frac{\partial \theta}{\partial X}+V \frac{\partial \theta}{\partial Y}=\frac{\partial^{2} \theta}{\partial X^{2}}+\frac{\partial^{2} \theta}{\partial Y^{2}}
$$

Boundary conditions

$$
\begin{gathered}
\text { At } X=0: U=V=0, \theta=1 \\
\text { At } X=1: U=V=0, \theta=0 \\
\text { At } Y=0: U=V=0, \frac{\partial \theta}{\partial Y}=0 \\
\text { At } Y=1: U=V=0, \frac{\partial \theta}{\partial Y}=0
\end{gathered}
$$

\section{NUMERICAL SOLUTION}

Eqns. (1-4) are subjected to the boundary conditions (Eq. 5). They are integrated numerically using a CFD based on the finite volume method.

\subsection{Effect of mesh size}

The effect of mesh size is shown in Table 1. For $\mathrm{Ra}=10^{5}$, $\mathrm{Da}=10^{-2}$ and $\varepsilon=0.4$, the maximum horizontal velocity, vertical velocity and average Nusselt number are presented with different mesh sizes. The grids have been optimized where a uniform mesh of $(182 \times 182)$ is used in $\mathrm{X}$ and $\mathrm{Y}$ directions.

Table 1. Effect of mesh size on maximum horizontal velocity, vertical velocity and average Nusselt number for $\mathrm{Ra}=10^{5}, \mathrm{Da}=10^{-2}$ and $\varepsilon=0.4$

\begin{tabular}{cccc}
\hline Mesh size & $\mathbf{U}_{\max }$ & $\mathbf{V}_{\max }$ & $\mathbf{N u}$ \\
\hline $82 \times 82$ & 14.069 & 20.3699 & 5.033571 \\
$102 \times 102$ & 13.85677 & 19.64757 & 4.941667 \\
$122 \times 122$ & 13.747 & 19.19972 & 4.837619 \\
$142 \times 142$ & 13.69577 & 18.96857 & 4.761693 \\
$162 \times 162$ & 13.68824 & 18.91078 & 4.705161 \\
$\mathbf{1 8 2} \times \mathbf{1 8 2}$ & $\mathbf{1 3 . 6 8 1 1 4}$ & $\mathbf{1 8 . 8 3 8 5 5}$ & $\mathbf{4 . 6 6 6 4 0 3}$ \\
$202 \times 202$ & 13.68114 & 18.83855 & 4.666303 \\
$222 \times 222$ & 13.68114 & 18.83855 & 4.666302 \\
\hline
\end{tabular}

\subsection{Validation}

The present numerical model has been validated by comparison with results due to Nithiarasu et al. [13]. The midheight temperature distribution for $\mathrm{Ra}=10^{5}, \mathrm{Da}=10^{-2}$ and $\varepsilon=$ 0.4 have been plotted and compared with results of Nithiarasu et al. (Figure 2). Good agreement has been obtained. In addition, Figure 3 shows for the two results the streamlines and isothermal lines and this for $\mathrm{Da}=10^{-6}, \mathrm{Ra}=10^{8}$ and $\varepsilon=$ 0.8 . The two results compare well as can be seen. Finally, Figure 4 presents another comparison of the two works based on streamlines and isothermal lines and this for $\mathrm{Da}=10^{-2}, \mathrm{Ra}$ $=10^{4}$ and $\varepsilon=0.6$. Good accordance has also been obtained.

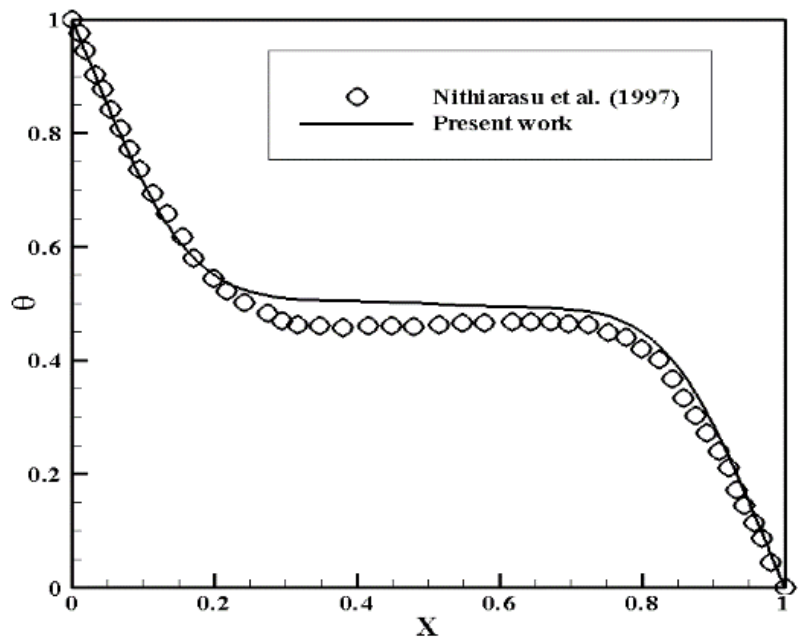

Figure 2. Comparison of the mid-height temperature distribution for $\mathrm{Ra}=10^{5}, \mathrm{Da}=10^{-2}$ and $\boldsymbol{\varepsilon}=0.4$ with results due to Nithiarasu et al. [13]
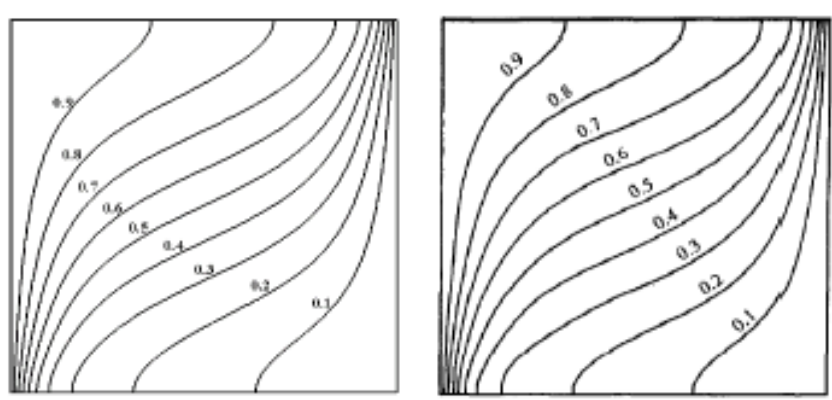

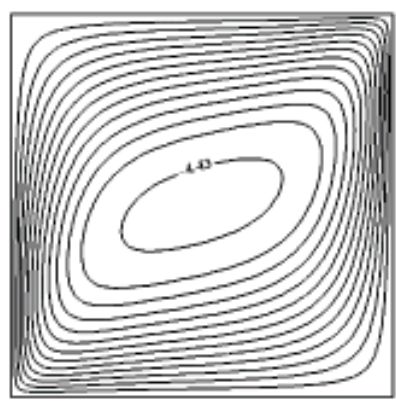

(a)

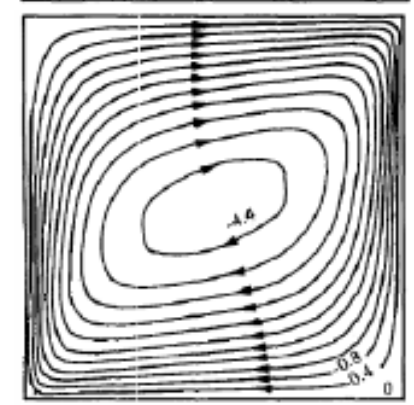

(b)
Figure 3. Comparison of streamlines and isothermal lines for $\mathrm{Da}=10^{-6}, \mathrm{Ra}=10^{8}, \varepsilon=0.8$. (a) present work, (b) Nithiarasu et al. (1997) 

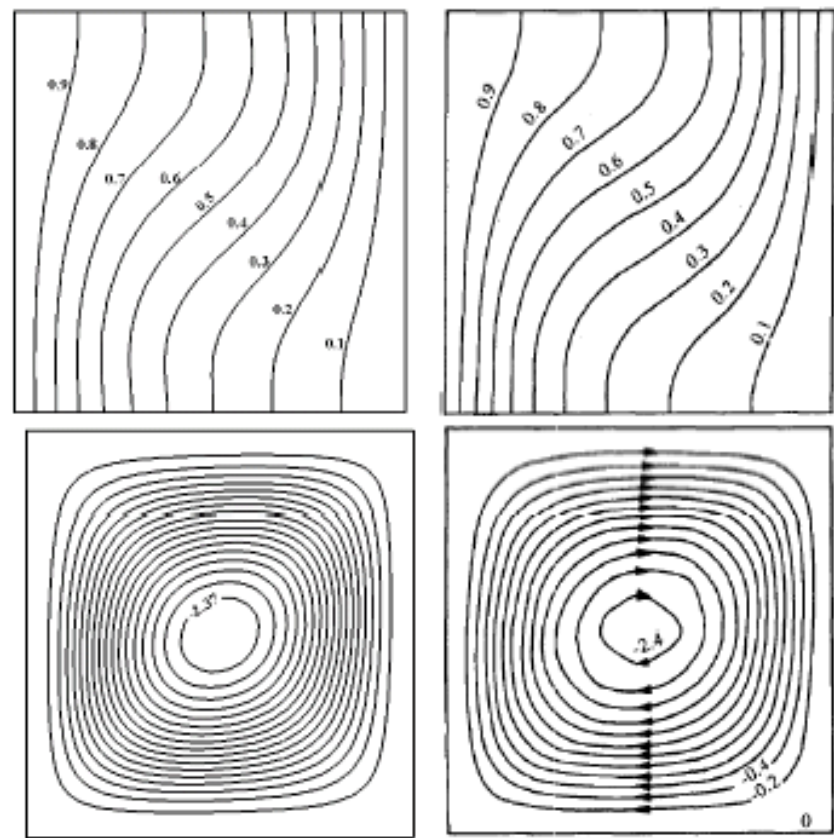

(a)

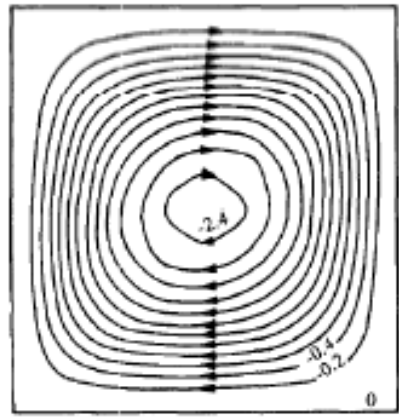

(b)

Figure 4. Comparison of streamline and isothermals $(\mathrm{Da}=$ $10^{-2}, \mathrm{Ra}=10^{4}, \boldsymbol{\varepsilon}=0.6$ ) a) present work, b) Nithiarasu et al. [13]

\section{RESULTS}

\subsection{Effect of Rayleigh number}

Figure 5 shows the effect of Rayleigh number on the velocity profiles at the middle of the cavity for $\mathrm{Da}=10^{-3}$ and $\boldsymbol{\varepsilon}$ $=0.7)$. Greater values of $\mathrm{Ra}$ lead to increasing velocity components. Stronger natural convection is observed near the hot wall. Figure 6 shows the average Nusselt number as function of Rayleigh number for a fixed value of Darcy number $\mathrm{Da}=10^{-3}$ and a given porosity $\boldsymbol{\varepsilon}=0.7$. One can notice that for $\mathrm{Ra}>10^{5}$, increasing Ra increases strongly the average Nusselt number. Figure 7 shows streamlines and isothermals for different $\mathrm{Ra}$ values and this for fixed Darcy number and porosity i.e. $\mathrm{Da}=10^{-3}$ and $\boldsymbol{\varepsilon}=0.7$. For low Ra numbers the isotherms are vertical and start getting deformed. The presence of significant convection currents is observed with clockwise cell. The heated wall works to move the fluid upward while the fluid moves downward near the cold wall. Greater values of Rayleigh number result in stronger circulation and the temperature contours are notably deformed which means that natural convection dominates the heat transfer.

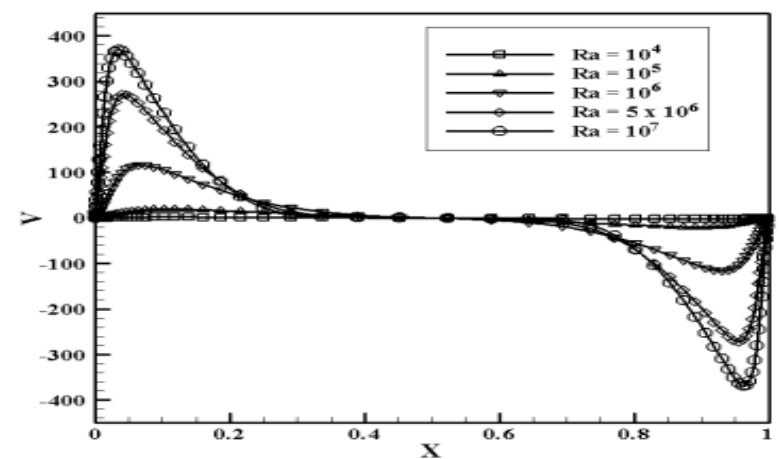

(a)

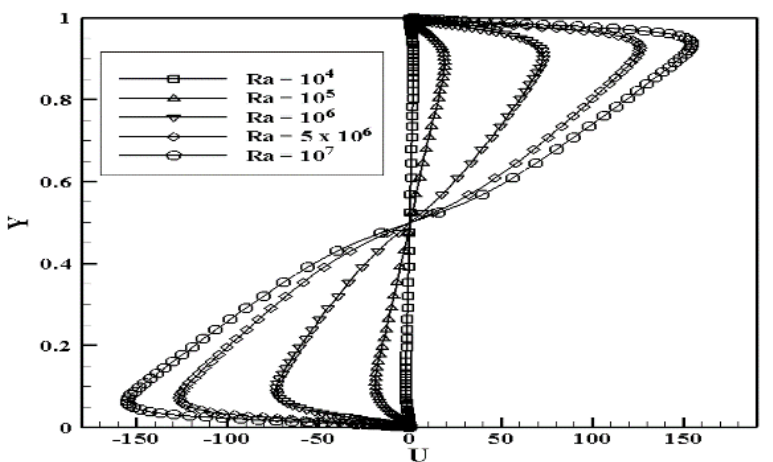

(b)

Figure 5. Profiles of velocity components horizontal velocity (a) and vertical velocity (b) in the middle of the cavity for various values of $\mathrm{Ra}\left(\mathrm{Da}=10^{-3}, \boldsymbol{\varepsilon}=0.7\right)$

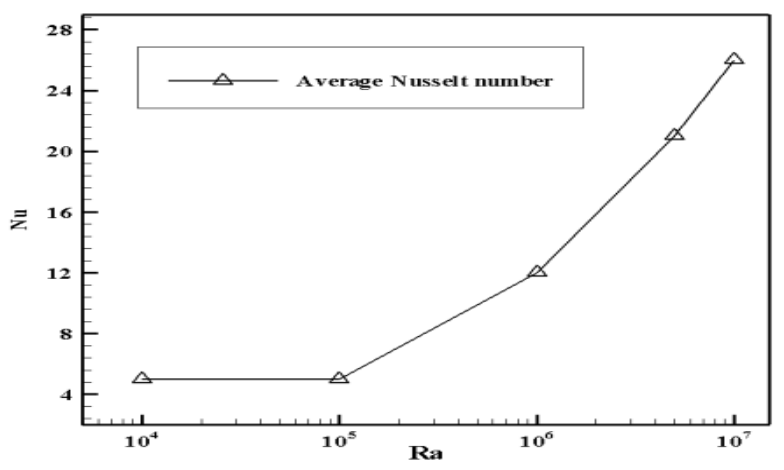

Figure 6. Average Nusselt number for various values of $\mathrm{Ra}$ $\left(\mathrm{Da}=10^{-3}, \boldsymbol{\varepsilon}=0.7\right)$

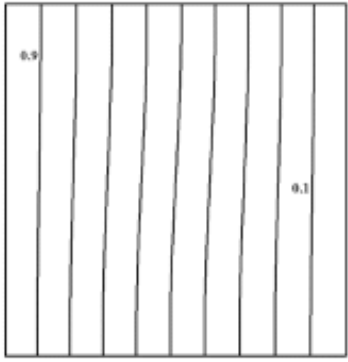

$\mathrm{Ra}=10^{4}$

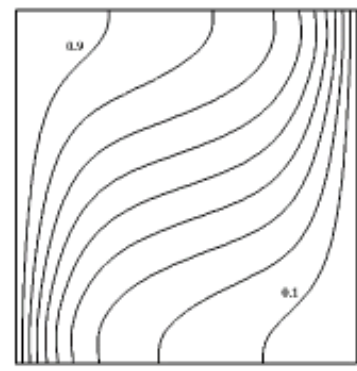

$\mathrm{Ra}=10^{6}$

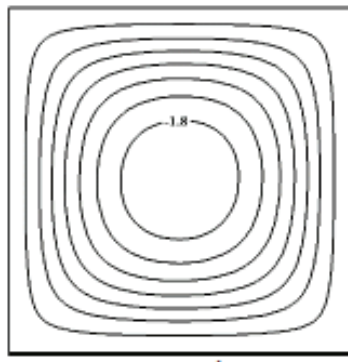

$\mathrm{Ra}=10^{4}$

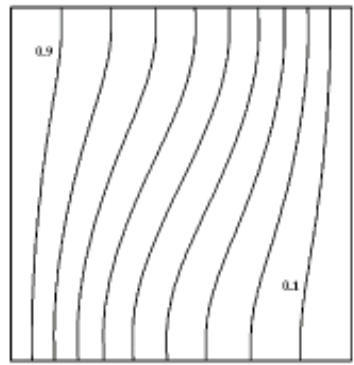

$\mathrm{Ra}=10^{5}$

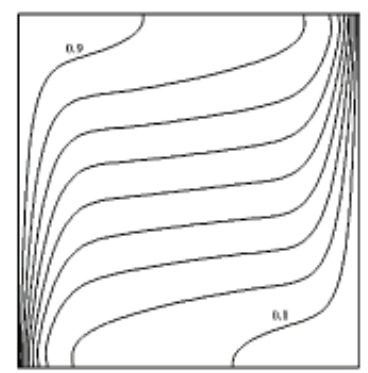

$\mathrm{Ra}=10^{7}$

(a)

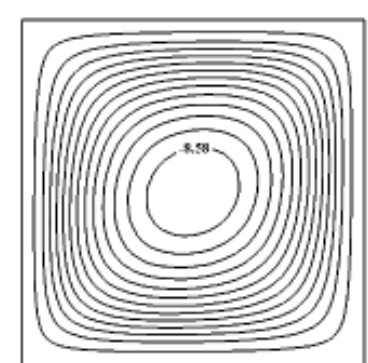

$\mathrm{Ra}=10^{5}$ 


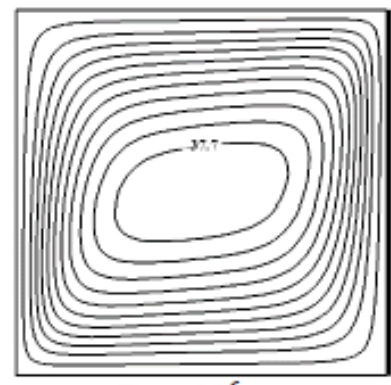

$\mathrm{Ra}=10^{6}$

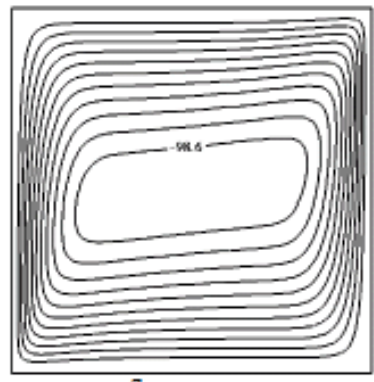

$\mathrm{Ra}=10^{7}$

(b)

Figure 7. Isothermal lines (a) and streamlines (b) for various values of $\mathrm{Ra}\left(\mathrm{Da}=10^{-3}, \boldsymbol{\varepsilon}=0.7\right)$

\subsection{Effect of Darcy number}

In order to investigate the effect of Darcy number on the fluid flow and heat transfer in the porous cavity, simulations with different values of Darcy number are carried out $(\mathrm{Da}=$ $10^{-5}, 10^{-4}, 10^{-3}, 10^{-2}$ ) where Rayleigh number and porosity are kept constant $\left(\mathrm{Ra}=10^{5}, \boldsymbol{\varepsilon}=0.7\right)$.

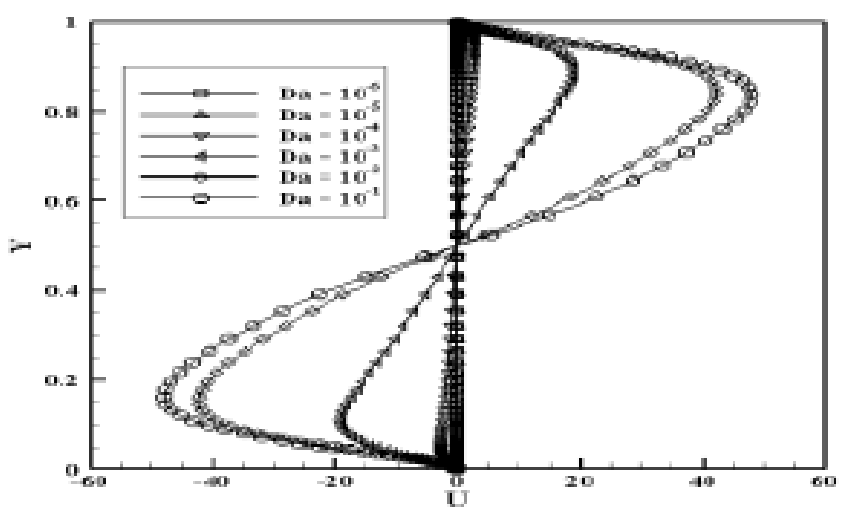

(a)

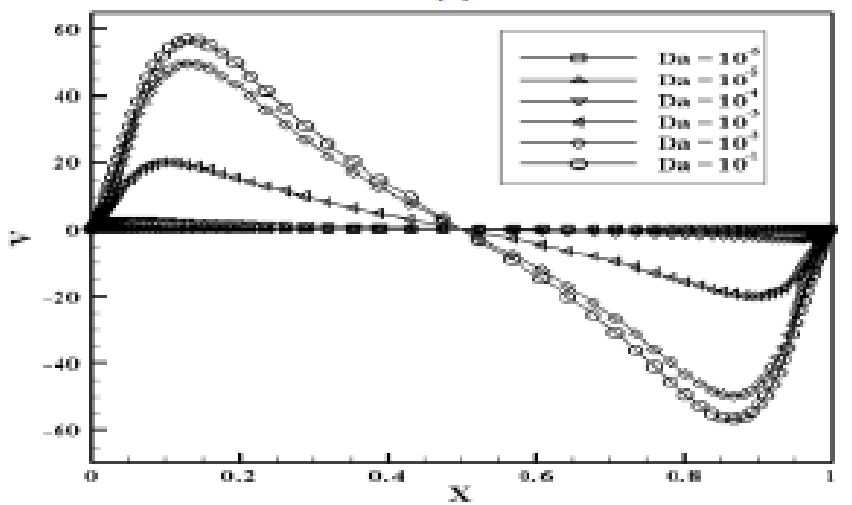

(b)

Figure 8. Profiles of velocity components horizontal velocity (a) and vertical velocity (b) in the middle of the cavity for various values of $\mathrm{Da}\left(\mathrm{Ra}=10^{5}, \boldsymbol{\varepsilon}=0.7\right)$

Figure 8 shows the effect of Da on the velocity profiles at the middle of the cavity. The velocity profiles are symmetric about the middle of the cavity. Greater values of Ra result in increasing velocity components. The maximum values are shown in the vicinity of the hot wall which is explained by stronger natural convection at this region. Increasing Darcy number resulted in lower velocities.

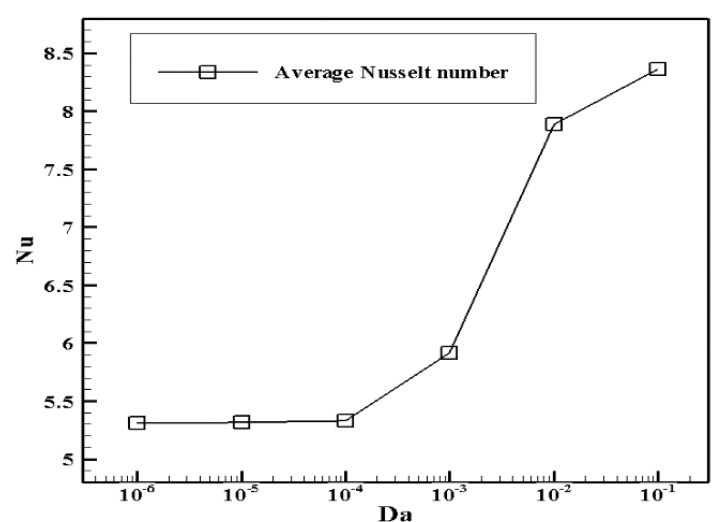

Figure 9. Average Nusselt number for various values of Da $\left(\mathrm{Ra}=10^{5}, \boldsymbol{\varepsilon}=0.7\right)$

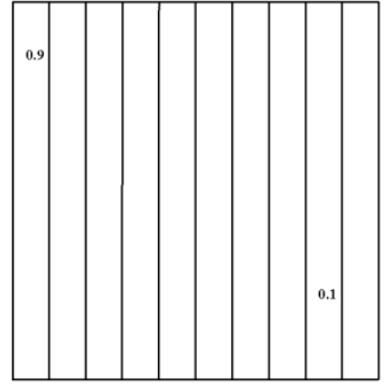

$\mathrm{Da}=10^{-6}$
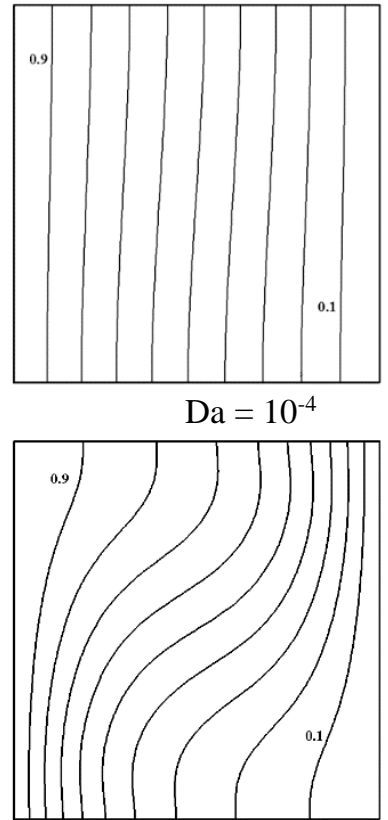

$\mathrm{Da}=10^{-2}$

(a)

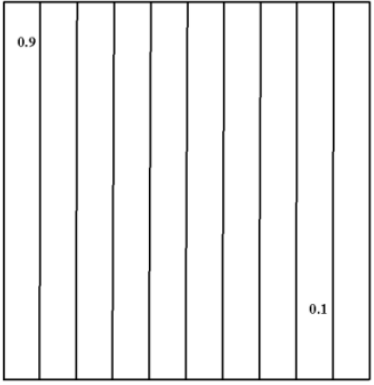

$\mathrm{Da}=10^{-5}$

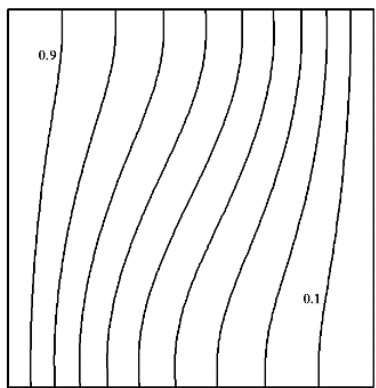

$\mathrm{Da}=10^{-3}$

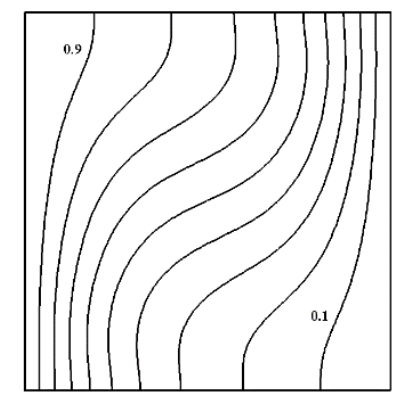

$\mathrm{Da}=10^{-1}$

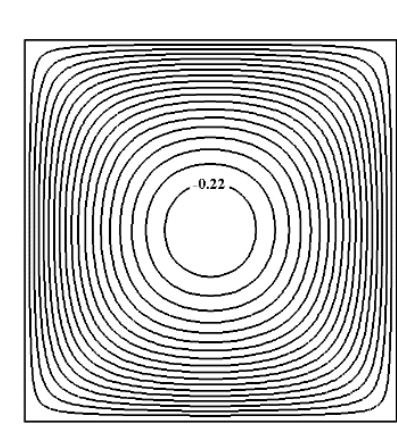

$\mathrm{Da}=10^{-5}$

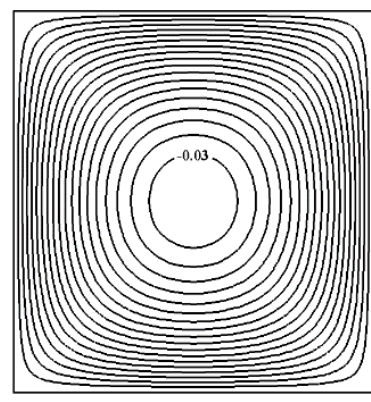

$\mathrm{Da}=10^{-6}$ 


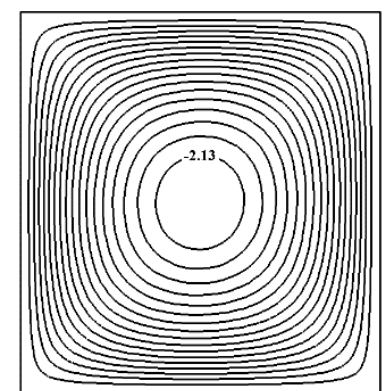

$\mathrm{Da}=10^{-4}$

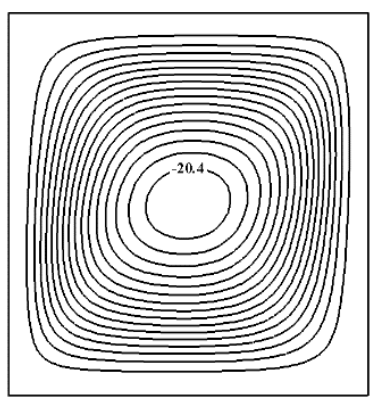

$\mathrm{Da}=10^{-2}$

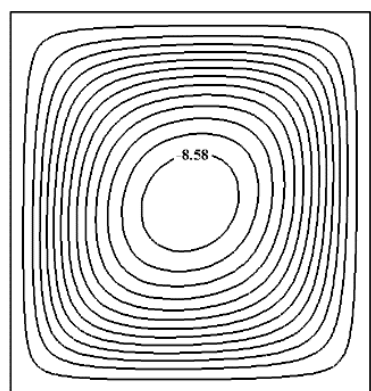

$\mathrm{Da}=10^{-3}$

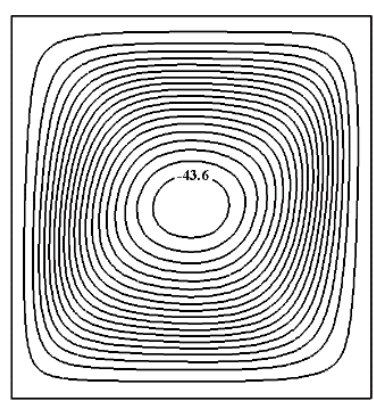

$\mathrm{Da}=10^{-1}$ (b)

Figure 10. Isothermal lines (a) and streamlines (b) for various values of $\mathrm{Da}\left(\mathrm{Ra}=10^{5}, \varepsilon=0.7\right)$

Figure 9 shows the average Nusselt number as function of Darcy number for $\mathrm{Ra}=10^{5}$ and $\boldsymbol{\varepsilon}=0.7$. For $10^{-4}<\mathrm{Da}<10^{-2}$, the average Nusselt number increases exponentially. Then there is practically no effect at lower values $\left(10^{-4} \geq \mathrm{Da} \geq 10^{-6}\right)$. For these values of Darcy the medium is no longer porous.
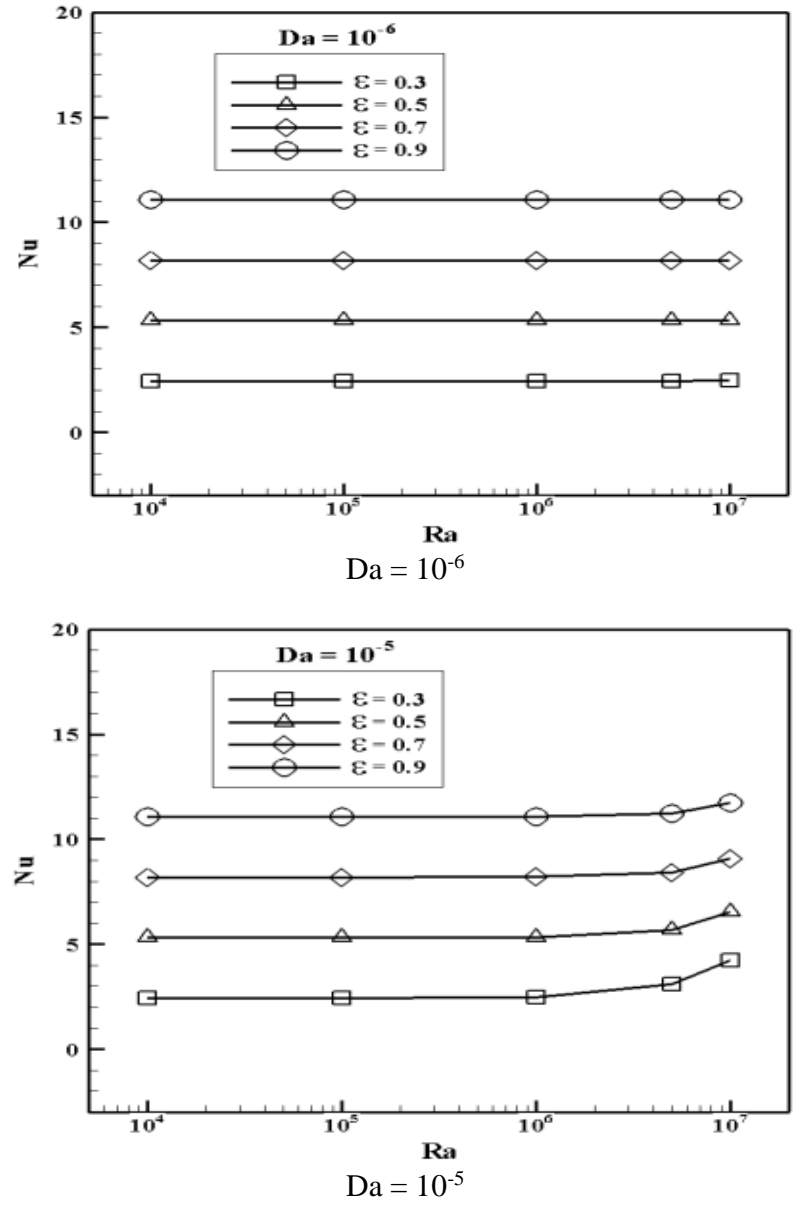
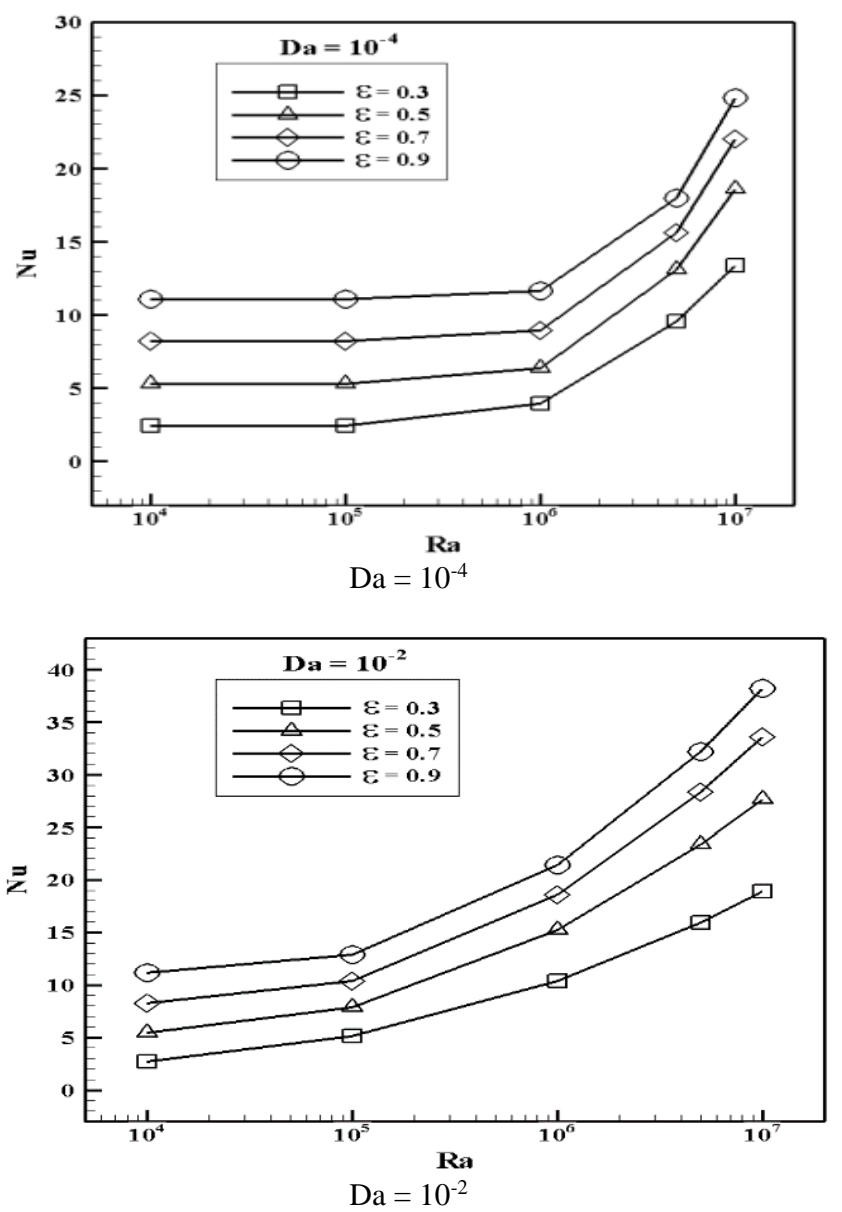

Figure 11. Effect of porosity on the heat transfer rate $(\mathrm{Nu}-$ Ra) for different Darcy number values

Figure 10 shows streamlines and isotherms patterns in the cavity. One can see that Darcy number has an effect on fluid flow and heat transfer. This effect is related to the cavity porosity. However, for low Darcy values $\mathrm{Da}=10^{-6}-10^{-4}$, heat convection is not significant due to the friction effect associated with low porosity (Brinkman term). Isotherms are vertical which means that conduction transfer mode is dominant in this case. But, for greater values of Darcy number (i.e. $10^{-3}$ à $10^{-1}$ ), convection heat transfer is significant which is accompanied with significant viscous effect that can be seen with distorted isotherms. The porosity of the cavity increases with increasing Da which results in decreasing viscous effect and hence fluid circulation. Streamlines show significant circulation near the cold wall.

\subsection{Effect of porosity}

The influence of porosity on fluid flow and heat transfer is shown in Figure 11. Different values of porosity and Darcy numbers are investigated. At higher values of $\mathrm{Da}$, significant effect of porosity on heat transfer is observed. But, for lower $\mathrm{Da}$ this effect is not significant $\left(\mathrm{Da}=10^{-5}\right)$ which could be neglected for $\mathrm{Da}=10^{-6}$.

\section{CONCLUSION}

Fluid flow and heat transfer have been investigated in a cavity filled with a storage porous media. The results of this numerical investigation have showed the effect of parameters 
governing heat transfer and fluid flow (i.e. Rayleigh number, Darcy number and porosity). Greater Rayleigh numbers resulted in stronger heat transfer by natural convection. Increasing Darcy numbers led to enhancing heat transfer rate whereas heat transfer by convection decreased with increasing porosity.

\section{ACKNOWLEDGMENT}

This work is supported by the Algerian Ministry of Higher Education and Scientific Research (DGRSDT-MESRS).

\section{REFERENCES}

[1] Nield, D.A., Bejan A. (2006). Convection in Porous Media, Springer.

[2] Loganathan, P., Sivapoornapriya, C. (2015). Unsteady heat and mass transfer effects on an impulsively started infinite vertical plate in the presence of porous medium. International Journal of Heat and Technology, 33(2): 6974. http://doi.org/10.18280/ijht.330211

[3] Ma, Z.S., Duan, L.B., Yao, S.G., Jia, X.W. (2015). Numerical study of natural convection heat transfer in porous media square cavity with multiple cold walls based on LBM. International Journal of Heat and Technology, 33(4): $\quad$ 69-76. http://doi.org/10.18280/ijht.330409

[4] Horton, C.W., Rogers, F.T. (1945). Convection current in a porous medium. Journal of Applied Physics, 16(6): 367-370. http://dx.doi.org/10.1063/1.1707601

[5] Lapwood, E.R. (1948). Convection of a fluid in a porous medium. Proceeding of Cambridge Philosophical Society, 44(4): 508-521. http://dx.doi.org/10.1017/S030500410002452X

[6] Revnic, C., Grosan, T., Pop, I., Ingham, D.B. (2009). Free convection in a square cavity filled with a Bidisperse porous medium. International Journal of Thermal Sciences, 48(10): 1876-1883. http://dx.doi.org/10.1016/j.ijthermalsci.2009.02.016

[7] Nield, D.A., Kuznetsov, A.V. (2008). Natural onvection about a vertical plate embedded in a Bidisperse porous medium. International Journal of Heat Mass Transfer, 51: 1658-1664.

https://doi.org/10.1016/j.ijheatmasstransfer.2007.07.011

[8] Rees, D.A.S., Nield, D.A., Kuznetsov, A.V. (2008). Vertical free convective boundary-layer flow in a Bidisperse porous medium. ASME Journal of Heat Transfer, 130: 1-9. https://doi.org/10.1115/1.2943304
[9] Bahloul, A. (2006). Boundary layer and stability analysis of natural convection in a porous cavity. International Journal of Thermal Sciences, 45(7): 635-642. https://doi.org/10.1016/j.ijthermalsci.2005.10.003

[10] Kalla, L., Mamou, M., Vasseur, P., Robillard, L. (1999). Multiple steady states for natural convection in a shallow porous cavity subject to uniform heat fluxes. International Communications in Heat and Mass Transfer, 26(6): 761-770. https://doi.org/10.1016/S07351933(99)00064-0

[11] Nawaf, H., Saeid, A., Mohamad, A. (2005). Natural convection in a square porous cavity with an oscillating wall temperature. International Journal of Numerical Methods for Heat \& Fluid Flow, 15(6): 555-566.

[12] Lauriat, G., Prasad, V. (1989). Non-Darcian effects on natural convection in a vertical porous enclosure. International Journal of Heat and Mass Transfer, 32(11): 2135-2148. https://doi.org/10.1016/00179310(89)90120-8

[13] Nithiarasu, P., Seetharamu, K.N., Sundararajan, T. (1997). Natural convective heat transfer in a fluid saturated variable porosity medium. International Journal of Heat and Mass Transfer, 40(16): 395-3967. https://doi.org/10.1016/S0017-9310(97)00008-2

\section{NOMENCLATURE}

$\begin{array}{ll}\mathrm{C}_{\mathrm{P}} & \text { Specific heat, } \mathrm{J} \cdot \mathrm{kg}^{-1} \cdot \mathrm{K}^{-1} \\ \mathrm{Da} & \text { Darcy number } \\ \mathrm{g} & \text { Gravitational acceleration, } \mathrm{m} \cdot \mathrm{s}^{-2} \\ \mathrm{~h} & \text { Heat transfer coefficient } \\ \mathrm{k} & \text { Thermal conductivity, W. } \mathrm{m}^{-1} \cdot \mathrm{K}^{-1} \\ \mathrm{Nu} & \text { Nusselt number } \\ \mathrm{Pr} & \text { Prandtl number } \\ \mathrm{Ra} & \text { Rayleigh number } \\ \mathrm{T} & \text { Temperature, }{ }^{\circ} \mathrm{C} \\ \mathrm{u}, \mathrm{v} & \text { Velocity components, } \mathrm{m} / \mathrm{s} \\ \mathrm{x}, \mathrm{y} & \text { Coordinate axes, } \mathrm{m}\end{array}$

\section{Greek symbols}

$\begin{array}{ll}\alpha & \text { Thermal diffusivity } \\ \beta & \text { Thermal expansion } \\ \varepsilon & \text { Porosity } \\ \mu & \text { Dynamic viscosity } \\ v & \text { Kinematic viscosity } \\ \psi & \text { Streamline function } \\ \rho & \text { Density }\end{array}$

